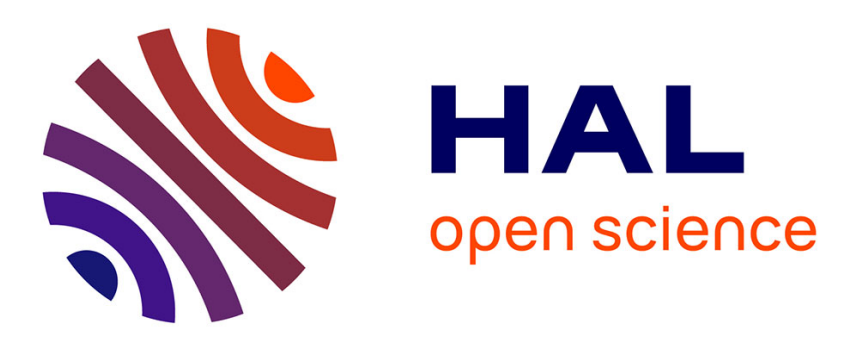

\title{
On the miscibility of PVDF/PMMA polymer blends: Thermodynamics, experimental and numerical investigations
}

Sara Aid, Anissa Eddhahak, Sofiane Khelladi, Zaida Ortega, Sana Chaabani, Abbas Tcharkhtchi

\section{To cite this version:}

Sara Aid, Anissa Eddhahak, Sofiane Khelladi, Zaida Ortega, Sana Chaabani, et al.. On the miscibility of PVDF/PMMA polymer blends: Thermodynamics, experimental and numerical investigations. Polymer Testing, 2019, 73, pp.222-231. 10.1016/j.polymertesting.2018.11.036 . hal-02466281

\section{HAL Id: hal-02466281 https://hal.science/hal-02466281}

Submitted on 11 May 2020

HAL is a multi-disciplinary open access archive for the deposit and dissemination of scientific research documents, whether they are published or not. The documents may come from teaching and research institutions in France or abroad, or from public or private research centers.
L'archive ouverte pluridisciplinaire HAL, est destinée au dépôt et à la diffusion de documents scientifiques de niveau recherche, publiés ou non, émanant des établissements d'enseignement et de recherche français ou étrangers, des laboratoires publics ou privés. 


\title{
On the miscibility of PVDF/PMMA polymer blends: Thermodynamics, experimental and numerical investigations
}

\author{
Sara Aid ${ }^{\mathrm{a}}$, Anissa Eddhahak ${ }^{\mathrm{a}, *}$, Sofiane Khelladi ${ }^{\mathrm{b}}$, Zaida Ortega ${ }^{\mathrm{c}}$, Sana Chaabani ${ }^{\mathrm{a}}$, \\ Abbas Tcharkhtchi ${ }^{\mathrm{a}}$ \\ a PIMM Laboratory, CNRS UMR 8006, Arts et Métiers ParisTech, 151 bd de l'Hôpital, 75013 Paris, France \\ ${ }^{\mathrm{b}}$ DynFluid Laboratory, Arts et Métiers ParisTech, 151 bd de l'Hôpital, 75013, Paris, France \\ ${ }^{\mathrm{c}}$ ULPGC, Calle Juan de Quesada, 35001, Las Palmas de Gran Canaria, Las Palmas, Spain
}

Keywords:

Polymer blend

PVDF/PMMA

Miscibility

Thermodynamics

Experimental

Numerical simulation

\begin{abstract}
A B S T R A C T
In this paper the miscibility of PVDF/PMMA blends was studied using different approaches: experimental tests, thermodynamics and numerical simulation. The first part of this study is devoted to the experimental work and aims to investigate the miscibility of blends by different experimental techniques. First, blends of PVDF/PMMA at different ratios were compounded and characterized using physico-chemical and rheological methods. The effect of PMMA content on the crystallization behavior of PVDF in the blend was experimentally investigated. At a second stage, the thermodynamic interaction parameter of Flory-Huggins was evaluated as a function of the PMMA proportion in the blends based on the experimental data related to the PVDF melting point and enthalpy. Besides, a numerical method has been developed using Fluent Ansys software to describe the coalescence phenomenon under different scenarios of viscosity ratios and grain sizes of polymers. The confrontation of the code simulation results with the experimental and thermodynamic approaches has shown a good agreement for reproducing the behavior of miscible polymers as well as their aptitude to form a homogeneous blend.
\end{abstract}

\section{Introduction}

The present study is involved in the framework of a great research project dealing with the WEEE (Waste Electrical and Electronic Equipment) recycling and the development of new blends derived from plastic wastes [1]. In this context, several studies of binary polymer mixtures containing crystalline polymers have been undertaken and have increasingly attracted significant attention of scientific and industrial communities [2]. Fluoropolymers, for example, are known for their excellent protective properties and are widely used as protective films and/or coating materials [3]. Poly(vinylidene fluoride) (PVDF) has good properties in terms of thermal stability, good chemical, oxidation and UV resistance as well as good mechanical properties, also offering a brilliant appearance. On the other hand, PVDF is one of the few semi-crystalline polymers to have five crystalline phases named $\alpha$, $\beta, \gamma, \delta$ and $\varepsilon[2,4-8]$, being $\alpha$ and $\beta$ the most frequently observed ones [4]. It is nevertheless very expensive and is often used mixed with other materials to deal with this disadvantage $[3,9,10]$. In order to lower its cost, on the one hand and/or to improve its adhesion properties, on the other one, it is often blended with poly(methyl methacrylate) (PMMA) polymer [11-14]. The latter has also many advantages, such as its good optical and insulating properties, for instance. Besides, PMMA is widely used in various industrial applications [6] due to its high rigidity and transparency, and can be distinguished by its low molecular weight, high transmittance and good chemical resistance [15]. The miscibility of PVDF and PMMA has been studied by several authors and their compatibility has been evaluated by different assays, such as the transparency of the blend, the solubility parameters, the Flory-Huggins interaction parameter, the transition and melting temperatures of the blend, etc. In particular, the decrease in the melting point in the crystallizable blends and the negative value of the interaction parameter were considered as proof of compatibility. From a thermodynamic point of view, Flory-Huggins parameter for two polymers 1 and 2, generally denoted $\chi_{12}$, is assumed to be an indicator of the affinity between two polymers in a mixture. Low interactions result in an increase of $\chi_{12}$, while a low $\chi_{12}$ indicates that both polymers exhibit preferential interactions favoring miscibility. In the case of mixtures with one of the components being semi-crystalline, the analysis of the melting behavior of mixtures is an important mean for assessing the miscibility of the polymers. Thermodynamic considerations predict that the chemical

\footnotetext{
* Corresponding author. Tel.: +33699247666/+33171936569.

E-mail addresses: sara.aid@ensam.eu (S. Aid), anissa.eddhahak@ensam.eu (A. Eddhahak), sofiane.khelladi@ensam.eu (S. Khelladi), zaida.ortega@ulpgc.es (Z. Ortega), sanachaabeni.enit@gmail.com (S. Chaabani), abbas.tcharkhtchi@ensam.eu (A. Tcharkhtchi).
} 
potential of a polymer is decreased by adding a miscible diluent. If the polymer is crystallizable, this decrease in the chemical potential will lead to a reduction of the melting point at equilibrium. The extent of the melting point drop in such systems provides a measure of the interaction parameter that is described according to the Flory-Huggins theory.

However, the thermodynamic parameters used for the miscibility determination, apart from being approximate in view of the different hypothesis it is based on, has been shown to be sometimes time consuming since it requires experimental data and thereby a long laboratory work.

In this context, the originality of the present work consists in developing a numerical simulation code in order to reproduce the miscibility of two grains of different polymers to form a homogeneous mixture. This numerical method can serve as an easy and fast predictive tool to investigate the miscibility behavior of different polymers under various conditions. The choice of PVDF/PMMA was potentially considered in this study as a "school case" for a good miscible blend. It shall be noted that in a previous work of the authors [25], the miscibility of these polymers was highlighted by the coalescence phenomenon observed between PVDF and PMMA grains in a hot stage plate under optical microscopy. The coalescence of molten polymer grains during which the interface between grains "matures" and evolves progressively to form an interphase [16,17] and finally a single particle is a good indicator of the affinity level and the high interaction between the considered polymers. The simulation results were confronted here to the experimental data and the thermodynamic findings, arriving to a general agreement of simulations and experimental data.

\section{Materials and methods}

\subsection{Materials description}

The materials used in the experiments were commercial polymers; the PolyVinyliDene Fluoride (PVDF) SOLEF 6008, a semi-crystalline thermoplastic polymer supplied by SOLVAY and the PolyMethyl Methacrylate (PMMA) VT825, an amorphous polymer, from ARKEMA. Table 1 summarizes some characteristics (glass transition temperature, $T_{g}$, melting temperature, $T_{m}$, and density) of the studied polymers, obtained from products datasheets.

\subsection{Blend preparation}

Before compounding, all the materials were dried in an oven in order to remove the absorbed water. Drying was performed at $80^{\circ} \mathrm{C}$ for $48 \mathrm{~h}$ for both polymers.

The blending of PVDF/PMMA was carried out using a classical screw extruder. Different blends of PMMA/PVDF were produced, containing $10 \%, 30 \%, 70 \%$ and $90 \%$ of PVDF (by weight). Processing was carried out at the temperature range $200{ }^{\circ} \mathrm{C}-220^{\circ} \mathrm{C}$ and a screw speed of $600 \mathrm{rpm}$. The extrudates were pelletized, dried at $80^{\circ} \mathrm{C}$ during $24 \mathrm{~h}$ and hot pressed at $200^{\circ} \mathrm{C}$.

\subsection{Physico-chemical characterization}

\subsubsection{Differential scanning calorimetry measurements (DSC)}

DSC measurements were carried out in a DSC Q10 V9.0 Build 278 from TA Instruments. The scans were performed under nitrogen atmosphere from $-80^{\circ} \mathrm{C}$ to $200^{\circ} \mathrm{C}$ at a heating rate of $5{ }^{\circ} \mathrm{C} / \mathrm{min}$. The

Table 1

Characteristics of the studied polymers.

\begin{tabular}{llll}
\hline Materials & $\boldsymbol{T}_{\boldsymbol{g}}\left({ }^{\circ} \mathrm{C}\right)$ & $\boldsymbol{T}_{\boldsymbol{m}}\left({ }^{\circ} \mathrm{C}\right)$ & Density $\left(\mathrm{g} / \mathrm{cm}^{3}\right)$ \\
\hline PVDF & -40 & 172 & $1.75-1.80$ \\
PMMA & 105 & - & 1.19 \\
\hline
\end{tabular}

sample mass was about $15 \mathrm{mg}$, using standard aluminum capsules.

The degree of mass crystallinity $\boldsymbol{X}_{\boldsymbol{c}}(\%)$ of the different blends was then calculated using the following relation:

$X_{C}=\frac{\Delta H_{m}}{\Delta H_{m}^{*}} \times 100(\%)$

Where $\Delta H_{m}^{*}$ is the melting heat per unit mass of the PVDF assumed to be $100 \%$ crystalline, and it is estimated at $104.7 \mathrm{~J} / \mathrm{g}$ [12], and $\Delta H_{m}$ is the heating enthalpy of the blends.

\subsubsection{Fourier transform infrared spectrometry (FTIR)}

FTIR spectra were obtained from a Perkin Elmer FTIR Spectrometry Frontier equipment on the different films of PVDF/PMMA blends obtained by hot press. The test of FTIR-MIR was carried out using transmission mode, 16 scans for each sample with a resolution of $4 \mathrm{~cm}^{-1}$, from 4000 to $400 \mathrm{~cm}^{-1}$.

\subsubsection{Wide-angle $X$-ray scattering (WAXS)}

The measurements were performed using a PANalytical X'Pert MRD device, powered by a Philips PW3040/60 X-ray generator and equipped with an X'Celerator detector. The diffraction data are acquired by exposing X-ray source powder samples of $\mathrm{Cu}-\mathrm{K} \alpha$ source, which has a characteristic wavelength $(\lambda)$ of $1.5406 \AA$. X-rays were generated from a $\mathrm{Cu}$ anode fed with $40 \mathrm{kV}$ and a current of $40 \mathrm{~mA}$. The data were collected over a range of $10-50$ with a $2 \theta$ pitch of $0.02^{\circ}$.

\subsubsection{Rheological tests}

The rheological measurements were carried out with an Anton Paar MCR 502 rheometer, at different temperatures from $200{ }^{\circ} \mathrm{C}$ to $240{ }^{\circ} \mathrm{C}$, in plate - plate configuration, in order to evaluate the miscibility of the PVDF/PMMA blends. The Cole-Cole method was used by evaluating the viscous and elastic responses of the complex shear modulus. The measurements were carried out at the temperature of $220^{\circ} \mathrm{C}$ with a frequency ranging from $0.1 \mathrm{~Hz}$ to $100 \mathrm{~Hz}$ and an imposed strain of $0.1 \%$.

\subsection{Thermodynamic approach}

In what follows, the crystalline component (PVDF) is denoted by polymer " 2 " which melts in the amorphous component (PMMA), denoted polymer " 1 ". The chemical potential $\mu_{2 u}^{1}$ per mole of a crystallizable polymer unit in the mixture relative to its chemical potential $\mu_{2 u}^{0}$ in the pure liquid is given by the standard approximation:

$\mu_{2 u}^{1}-\mu_{2 u}^{0}=R T \frac{V_{2}}{V_{1}}\left(\frac{\ln \varphi_{2}}{m_{2}}+\left(\frac{1}{m_{2}}-\frac{1}{m_{1}}\right)\left(1-\varphi_{2}\right)+\chi_{12}\left(1-\varphi_{2}\right)^{2}\right)$

Where $V_{i}$ and $m_{i}$ are the molar volume and the degree of polymerization, respectively, of the polymer $i$ and $\chi_{12}$ is the polymer/ polymer interaction parameter. Whereas $\varphi_{1}$ and $\varphi_{2}$ represent the volume fraction of polymer 1 and 2, respectively. $R$ is the gas constant and $T$ is the absolute temperature.

On the other hand, the difference in the chemical potentials between a crystalline polymer unit $\mu_{2 u}^{c}$ and the same unit in the pure liquid state $\mu_{2 u}^{0}$ can be written as:

$\mu_{2 u}^{c}-\mu_{2 u}^{0}=-\left(\Delta H_{2 u}-T \Delta S_{2 u}\right)=-\Delta H_{2 u}\left(1-T_{m} / T_{m}^{0}\right)$

where $\Delta H_{2 u}$ and $\Delta S_{2 u}$ are respectively the enthalpy and entropy of fusion per mole of repeat unit and $\Delta H_{2 u} / \Delta S_{2 u}$ is assumed to be independent of temperature and equal to the equilibrium melting temperature $T_{m}^{0}$.

At the melting point, the chemical potential of the crystalline component in the crystalline and liquid phases should be identical. From equations (2) and (3) one obtains: 


$$
\begin{aligned}
& \frac{1}{T_{m}^{0}\left(\varphi_{2}\right)}-\frac{1}{T_{m}^{0}} \\
& =-\frac{R \cdot V_{2}}{\Delta H_{2 u} V_{1}}\left[\frac{\ln \varphi_{2}}{m_{2}}+\left(\frac{1}{m_{2}}-\frac{1}{m_{1}}\right)\left(1-\varphi_{2}\right)+\chi_{12}\left(1-\varphi_{2}\right)^{2}\right]
\end{aligned}
$$

For $m_{2}, m_{1}>>1$ the combinatorial term in equation (4) can be neglected and the equation is reduced to:

$\frac{1}{T_{m}^{0}\left(\varphi_{2}\right)}-\frac{1}{T_{m}^{0}}=-\frac{R V_{2}}{\Delta H \cdot V_{1}} \chi_{12}\left(1-\varphi_{2}\right)^{2}$

In this expression, $T_{m}^{0}$ and $T_{m}^{0}\left(\varphi_{2}\right)$ represent the melting temperatures of an infinite crystal in equilibrium with the pure melt and with a mixture of concentration $\varphi_{2}$, respectively [18].

\subsection{Numerical simulation}

This section is dedicated to the simulation of the coalescence phenomenon of a two-phase flow system; PVDF and PMMA polymers using a Fluent Ansys Software which is a CFD (Computational Fluid Dynamics) tool. CFD is a numerical tool applied to fluid mechanics that allows the study of fluid flows to improve the design of structures such as aircraft wings and automobile parts. In the field of fluid simulation, the physical aspects of flow are governed by three fundamental principles of mass, momentum and energy conservation. These principles are expressed as a function of partial differential equations. CFD software allows solving these equations in a simple and accurate way. Indeed, the first task of this technique consists in creating the geometry to study [19]. Then, this needs to be discretized into small elementary volumes called "Control Volumes", where the partial differential equations are solved, this step is called "Meshing". Then the model to use needs to be chosen; CFD tools provides several models with different levels of representativity depending on the reliability of each specific software. Then, the boundary conditions must be put in place judiciously to ensure that the problem is well posed, and finally, the equations are solved.

The retained model for this purpose, is a two-phase flow model based on Euler equations supplemented by a pressure law describing the behavior of the mixture of the two phases [20]. This homogenous numerical model called "Mixture model" can be appropriate to represent a miscible multiphase blend of polymers. This approach is based on a multiphasic model where the properties of the phases are derived from the individual phases properties by a mixture law, as follows [21-25]:

$$
\begin{gathered}
\rho_{m}=\sum_{k=1}^{n} \alpha_{k} \rho_{k} \\
\mu_{m}=\sum_{k=1}^{n} \alpha_{k} \mu_{k}
\end{gathered}
$$

$\sum_{\mathrm{k}=1}^{\mathrm{n}} \alpha_{\mathrm{k}}=1$

Where $\rho, \mu$ and $\alpha$ denote the density, the viscosity and the volume fraction, respectively.

The mass fraction noted $\omega_{k}$ is defined as follows

$\omega_{\mathrm{k}}=\frac{\rho_{k}}{\rho}$

Generally, the mass fraction is used where mass diffusion is considered in the system. In this case study, mass transfer phenomenon between phases are not introduced to simplify the problem.

For the simulation, an isothermal flow was considered and consequently the classical energy equation is neglected. Thus, the system of equations to solve is given by the mass conservation equation is expressed as: $\frac{\partial \rho_{m}}{\partial t}+\overrightarrow{V_{m}} \cdot \vec{\nabla} \rho_{m}=0$

and the momentum conservation equation as:

$\frac{\partial \rho_{m} \overrightarrow{V_{m}}}{\partial t}+\overrightarrow{V_{m}} \cdot \vec{\nabla}\left(\rho_{m} \overrightarrow{V_{m}}\right)=-\overrightarrow{\nabla \mathrm{P}}+\Delta \underline{\underline{\tau_{m}}}+\rho_{m} \vec{g}+\vec{F}$

where

$\underline{\underline{\tau_{m}}}=2 \mu_{m} \underline{\underline{D}}=\mu_{m}\left(\vec{\nabla} \cdot \overrightarrow{V_{m}}+\vec{\nabla}^{t} \overrightarrow{V_{m}}\right)$

$\overrightarrow{V_{m}}=\frac{\sum_{k=1}^{n} \alpha_{k} \mu_{k} \overrightarrow{v_{k}}}{\rho_{m}}$

being $\vec{V}_{m}$ the average velocity.

\section{Results and discussion}

\subsection{Effect of the PMMA on PVDF crystallization}

\subsubsection{Thermal results}

DSC thermograms for heating and cooling cycles are depicted in Figs. 1 and 2, respectively. As shown in Fig. 1, pure PVDF exhibits a single melting peak at $173^{\circ} \mathrm{C}$ which could be attributed to the presence of $\alpha$ phase crystals. This figure also shows that the melting temperature of PVDF/PMMA blends decreases with the increasing PMMA content in the blend. For instance, the $T_{m}$ of PVDF/PMMA blend is $170{ }^{\circ} \mathrm{C}$ for $30 \%$ PMMA blends.

Fig. 2 shows that the blend with $30 \%$ of PMMA exhibits two crystallizations peaks. This phenomenon is explained in the literature by the melting of two distinct populations of crystals. In fact, the $\beta$ crystals melt at a higher temperature than $\alpha$ crystals $[5,26]$.

The degree of crystallinity of the different PVDF/PMMA blends can be determined by measuring the area under the crystalline melting endothermic peaks and then by using the afore mentioned equation (1). The different results are listed in Table 2, where it is observed that the crystallinity and the melting temperatures for the blends are reduced when increasing the PMMA content. The important decrease in the crystallinity and the melting point is indicative of the good affinity and miscibility between PVDF and PMMA polymers; besides, it is wellknown that the PMMA is largely amorphous and does not contribute to the heat of fusion. In fact, the decrease of $T_{m}$ in the different blends with the addition of PMMA is explained by the thermodynamic effect which

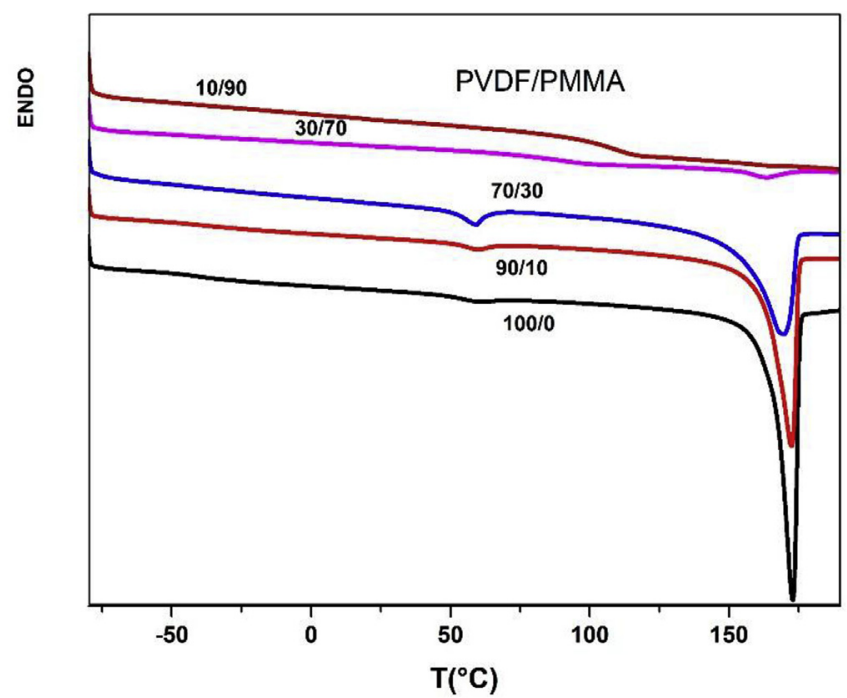

Fig. 1. DSC thermograms of PVDF/PMMA blends (case of the heating cycle). 


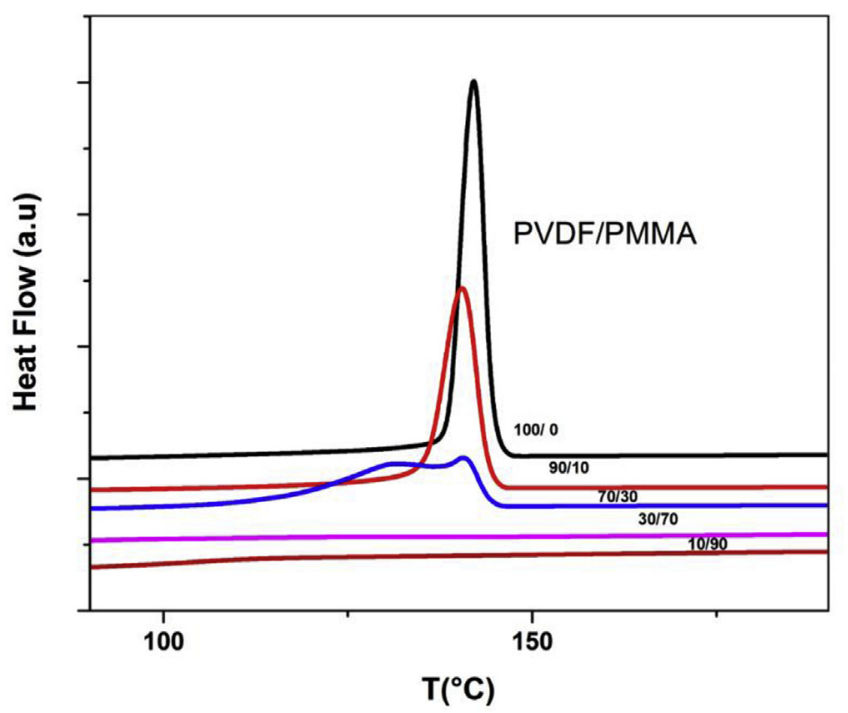

Fig. 2. DSC thermograms of PVDF/PMMA blends (case of the cooling cycle).

Table 2

The DSC parameters for PVDF/PMMA blends.

\begin{tabular}{lllllll}
\hline PVDF/PMMA (\%) & $100 / 0$ & $90 / 10$ & $70 / 30$ & $30 / 70$ & $10 / 90$ & $0 / 100$ \\
\hline $\boldsymbol{T}_{\boldsymbol{m}}\left({ }^{\circ} \boldsymbol{C}\right)$ & 173 & 172 & 169 & 163 & - & - \\
$\Delta \boldsymbol{H}_{\boldsymbol{m}}(\boldsymbol{J} / \mathrm{g})$ & 43 & 39 & 31 & 2 & - & - \\
$\boldsymbol{T}_{\boldsymbol{c}}\left({ }^{\circ} \boldsymbol{C}\right)$ & 142 & 140 & 132 & - & - & - \\
& & & 141 & & & \\
$\Delta \boldsymbol{H}_{\boldsymbol{c}}(\boldsymbol{J} / \mathbf{g})$ & 51 & 46 & 1 & - & - & \\
$\boldsymbol{T}_{\boldsymbol{g}}\left({ }^{\circ} \boldsymbol{C}\right)$ & -40 & -40 & 65 & 83 & 108 & 114 \\
$\boldsymbol{X}_{\boldsymbol{c}}(\%)$ & 41 & 42 & 41 & 5 & - & - \\
\hline
\end{tabular}

occurs in a crystalline polymer-diluent mixture, valid in the case of crystalline polymer-amorphous polymer system, so an increase of the diluent (PMMA) reduces the melting point of the polymer crystals (PVDF). However, one can see that $10 \%$ of PMMA in the blend increase the crystallinity of the PVDF/PMMA blend. This observation will be discussed in next section, together with further characterization results.

\subsubsection{FTIR and WAWS analysis}

Fig. 3 contains the infrared spectra of the different PVDF/PMMA mixtures. The characteristic peaks of the $\beta$ phase $\left(840 \mathrm{~cm}^{-1}\right.$ and $1279 \mathrm{~cm}^{-1}$ essentially) appear in the PVDF/PMMA mixtures for a proportion up to $30 \%$ PMMA. Beyond this proportion, the representative peaks of the $\beta$ phase disappear, whereas the bands corresponding to the $\alpha$ phase decrease in intensity or disappear $\left(614 \mathrm{~cm}^{-1}\right.$, $766 \mathrm{~cm}^{-1}, 795 \mathrm{~cm}^{-1}, 855 \mathrm{~cm}^{-1}$ and $976 \mathrm{~cm}^{-1}$ ). It is then clear that PMMA impacts the crystallization of PVDF.

From Fig. 4, it can be seen that the elongation frequency at $1721 \mathrm{~cm}^{-1}$, which corresponds to the carbonyl group $(C=O)$ of PMMA, is shifted to higher wavelengths $\left(1724 \mathrm{~cm}^{-1}\right)$ in the PVDF/ PMMA mixtures. This shift is due to the specific interactions between the carbonyl group of PMMA, on the one hand, and the $\mathrm{CH}_{2}$ group of PVDF, on the other one. This finding is indicative of the formation of a mixture [8].

In addition, the relationship proposed by Martin et al. [7] can be used to determine the amount of $\beta$ phase in the pure PVDF:

$F(\beta)=\frac{A_{\beta}}{\frac{K_{\beta}}{K_{\alpha}} A_{\alpha}+A_{\beta}}$

Where $F(\beta)$ represents the content of the $\beta$ phase, $\mathrm{A}_{\beta}$ and $\mathrm{A}_{\alpha}$ are respectively the absorbances at $766 \mathrm{~cm}^{-1}$ and $840 \mathrm{~cm}^{-1}, k_{\beta}$ and $k_{\alpha}$ the absorption coefficients corresponding to the respective wave numbers $6.1 .10^{4}$ and $7.7 \times 10 \mathrm{~cm}^{2} / \mathrm{mol}$.

Consequently, from Equation (14), $F(\beta)=44.88 \%$. By analogy, the $\beta$-phase content in the PVDF/PMMA mixtures with major contents in PVDF (10\% and $30 \%$ of PMMA) can be calculated, and results are shown in Fig. 5.

It is clearly observed that the $\beta$ content decreases for contents in PMMA over $10 \%$, while this small amount of PMMA increases the crystallinity in the blend. This finding is in a good agreement with the previous DSC thermal results in connection with the total disappearance of the crystallization and melting peaks at 70\% of PMMA. However, further blends of PVDF/PMMA with PMMA proportions ranging from $10 \%$ to $30 \%$ are needed to identify more accurately the amount of PMMA at which the crystallization of the blend decreases.

In order to confirm the impact of the addition of PMMA in the crystalline phase of PVDF, it was useful to perform a wide-angle X-ray diffraction analysis (WAXS) on the different PVDF/PMMA blends.

Fig. 6 shows WAXS spectra of pure PVDF, pure PMMA and the different mixtures of PVDF/PMMA. From the spectrum of the pure PVDF, the following diffraction peaks can be distinguished: $18.18^{\circ}$, $26.98^{\circ}$, and $46.43^{\circ}$ which correspond to the diffractions in the ( 020 ), (0 221 ) (2 2 0) plans respectively, all characteristics of the $\alpha$ phase of PVDF. There is also a peak at $20.11^{\circ}$ corresponding to the plane $\left(\begin{array}{lll}1 & 1 & 0\end{array}\right)$ characteristic of the $\beta$ phase. The pure PMMA has an amorphous phase which is characterized by two amorphous waves: the first is the largest one and centered at $2 \theta=13^{\circ}$ and the second is the smallest bump at $2 \theta=30^{\circ}$.

From the analysis of the different spectra as a function of the PMMA content, it has been found that the peak at $46.43^{\circ}$, characteristic of the $\alpha$ phase, disappears when the PMMA proportion reaches $30 \%$. The peak at $20.10^{\circ}$ with reference to the diffractions in the $\left(\begin{array}{lll}1 & 1 & 0\end{array}\right)$ plane, characteristic of the $\beta$ phase, shows a progressive decrease (without disappearance) of the relative intensity of the incipient peak. This shows that the mixtures always present crystals of the $\beta$ phase of PVDF up to a PMMA content of $30 \%$. Beyond this, characteristic peaks of the $\alpha$ and $\beta$ crystalline phases are no longer found in the spectrum and the amorphous curvature becomes more and more obvious as the proportion of PMMA increases. This observation illustrates the high level of interactions between the two polymers and the PVDF crystallization behavior with the addition of PMMA and indicates the involvement of PMMA molecules in the crystallization process of PVDF. Furthermore, the decrease in the PVDF crystallization with the addition of PMMA can also be explained by the fact that the diffusion of PVDF towards the crystalline surface, would have been hampered by the interactions with PMMA [2,4-6,27,28].

\subsubsection{Rheological behavior/Cole-Cole method}

It's known that materials exhibit a linear viscoelastic (LVE) behavior in the small strain region, i.e, the elastic modulus $\left(G^{\prime}\right)$ and loss modulus $\left(G^{\prime}\right)$ are independent of the applied strain $[29,30]$.

Fig. 7 shows the evolution of $G^{\prime}$ as a function of the applied deformation (from 0.1 to $100 \%$ ) at $220{ }^{\circ} \mathrm{C}$ and at a frequency $\mathrm{f}=100 \mathrm{~Hz}$, for the various PVDF/PMMA blends $(0 \%, 30 \%, 70 \%$ and $100 \%$ of PMMA). The presence of a flat area in the curves corresponding to the LVE behavior of the materials can be observed. When the applied deformation exceeds the critical value, the shear modulus drops sharply. From Fig. 7, it can be determined that PVDF/PMMA mixtures show a linear behavior up to a maximum deformation of $10 \%$. Thus, in order to ensure that the blend exhibit LVE behavior, all the measurements will be performed at a constant small deformation of $0.1 \%$ using a frequency sweep mode.

The method developed by Cole-Cole representing the relationship between the real and the imaginary parts of the complex viscosity, respectively $\left(\eta^{\prime}, \eta^{\prime \prime}\right)$ allows the validation of the polymer blends compatibility by observing the shape of the obtained curves. It is commonly admitted that when a blend is readily miscible and homogeneous, the 


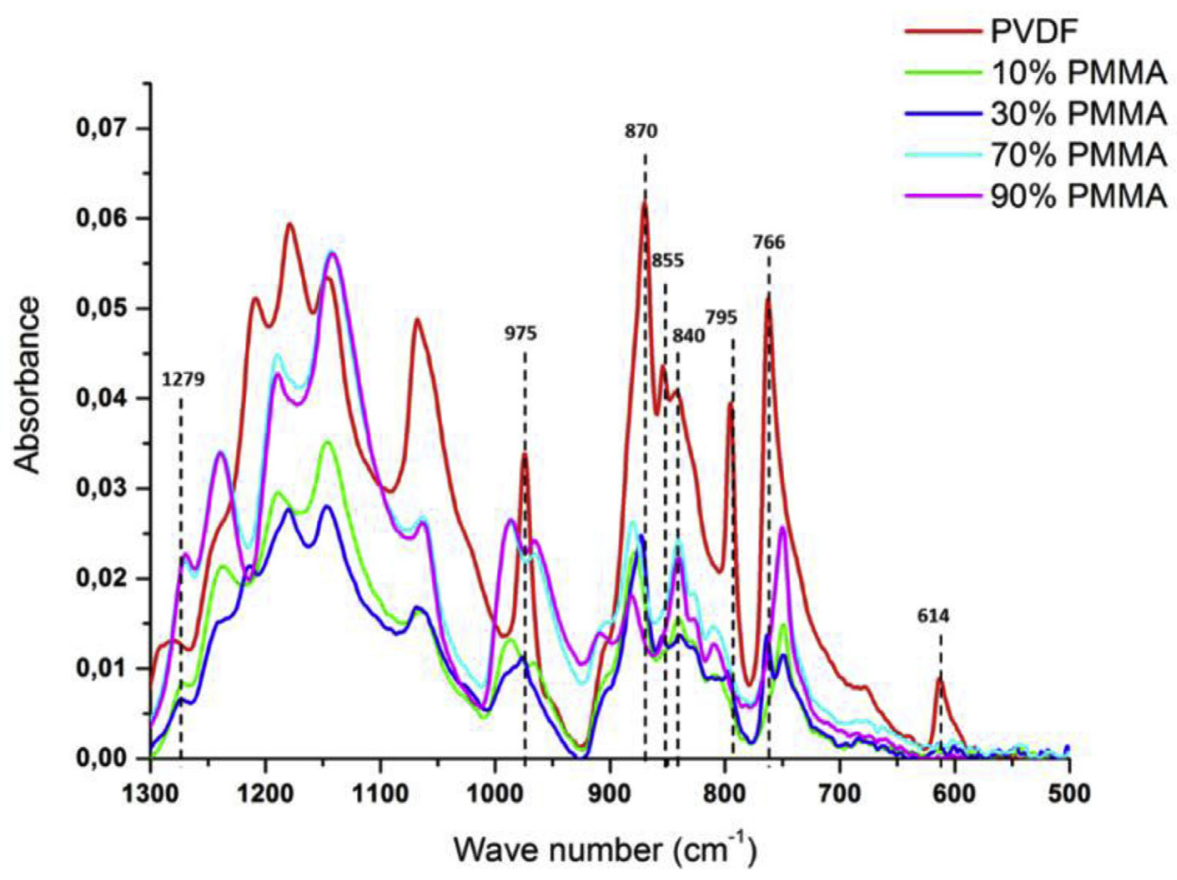

Fig. 3. FTIR transmission spectra of PVDF/PMMA blends compared to pure PVDF spectrum.

curves $\eta^{\prime \prime}=\mathrm{f}\left(\eta^{\prime}\right)$ are quite smooth and have the shape of a semicircle. However, the occurrence of deviations or disordered points on the curve can reflect a poor homogeneity of the blends components [31]. Fig. 8 presents plots of $\eta^{\prime \prime}$ versus $\eta^{\prime}$ for the different PVDF/PMMA blends. As seen in this figure, all the curves of the blend present a shape of a semicircle which is synonym of a good homogeneity of these blends and as well as of a good miscibility between its components. This finding supports the afore mentioned results about the good miscibility of PVDF and PMMA polymers.

\subsection{Thermodynamics interaction parameter}

In this section, the interaction parameter according to the expression proposed by Nishi and Wang [22] is calculated. Indeed, the authors analyzed the melting temperature of a crystalline polymer (component 2 ) in the presence of a polymeric diluent (component 1) using Scott's expression [23] for the chemical potentials in a mixture of binary polymers. The resulting equation for the melting temperature decrease is:

$\frac{1}{T_{m}}=-\frac{R V_{2 u}}{\Delta H_{f u} V_{1 u}} \chi_{12} v_{1}^{2}+\frac{1}{T_{m}^{0}}$

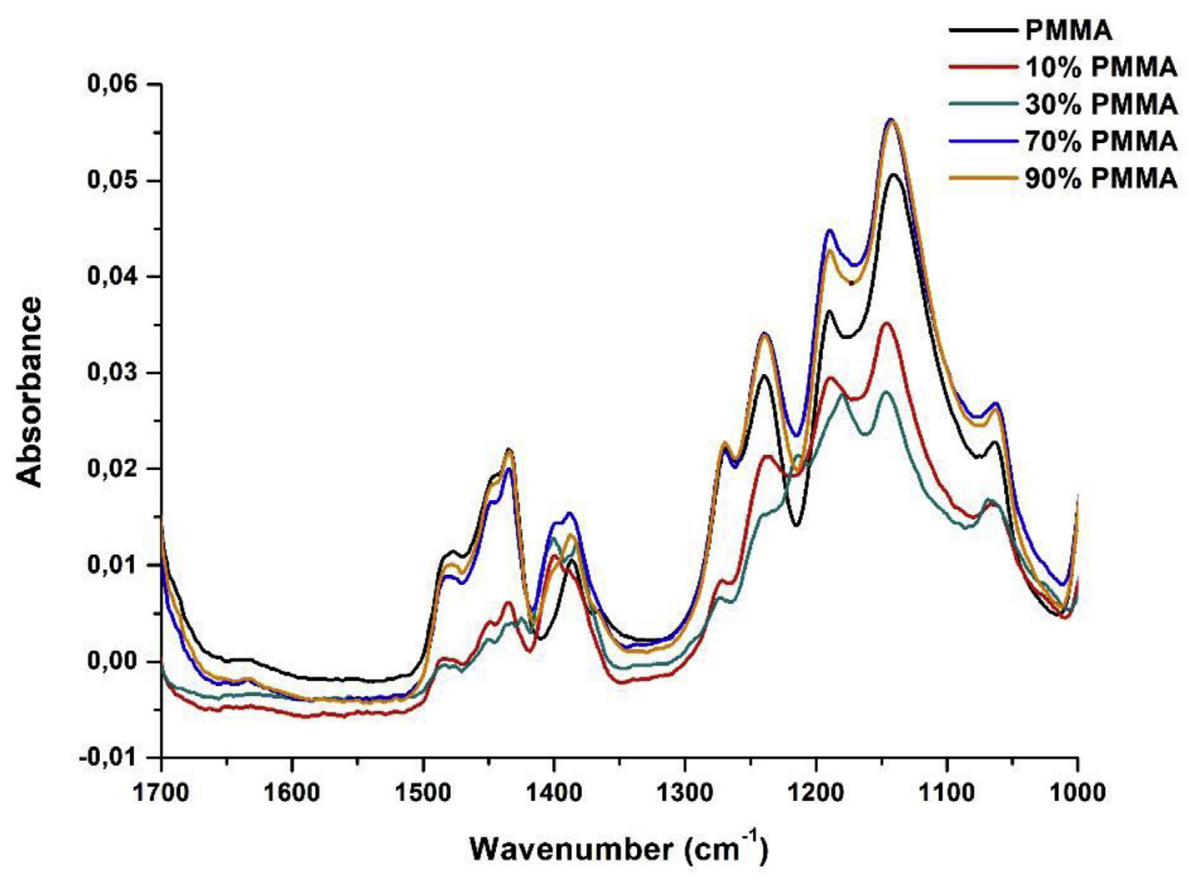

Fig. 4. FTIR transmission spectra of PVDF/PMMA blends compared to pure PMMA spectrum. 


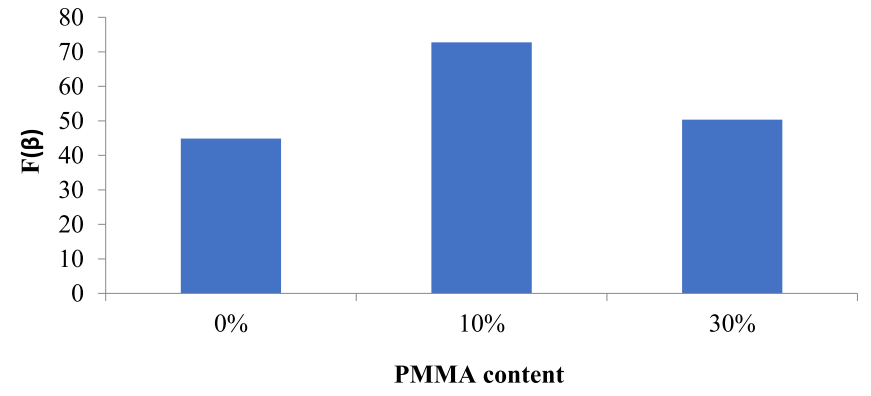

Fig. 5. Evolution of the $\beta$ content in PVDF/PMMA estimated according to Martin relation.

Where:

$V_{1 u}$ is the molar volume of the repeating units in PMMA (82, 83.3 and $84 \mathrm{~cm}^{3} / \mathrm{mol}$ for isotactic, atactic et syndiotactic PMMA, respectively) [32].

$V_{2 u}$ is the molar volume of the repeating units PVDF and equal to $36.4 \mathrm{~cm}^{3} / \mathrm{mol}$.

$\mathrm{R}$ is the universal gas constant $=1.99 \mathrm{cal} / \mathrm{mol} \mathrm{K}$.

$\Delta H_{f u}$ is the molar heat fusion of the repeating units in PVDF and equal to $1.60 \mathrm{kcal} / \mathrm{mol} T_{m}$ is the melting point of PVDF crystal in the mixture (K).

$T_{m}^{0}$ is the melting point of pure PVDF and equal to $445.95 \mathrm{~K}$ (measured by DSC).

$\chi_{12}$ is the interaction parameter.

$\nu_{1}$ is the volume fraction of PMMA.

In this study the used polymer is a commercial atactic PMMA. Equation (15) can be then used to obtain the interaction parameter for PVDF/PMMA mixtures at $10 \%, 30 \%$ and $90 \%$ of PMMA (Table 3 ). Results of de $\chi_{12}$ calculations for $0.1<\nu_{1}<0.7$ show a negative value for the whole interval. A negative interaction parameter indicates that the PVDF/PMMA blend is thermodynamically stable in the molten state. This allows stating that both components are miscible. Indeed, this is explained by the fact that, in this case, the adhesive forces between the two polymers 1 and 2 are greater than the cohesive forces between polymer 1 /polymer 1 and polymer 2/polymer 2 [24].

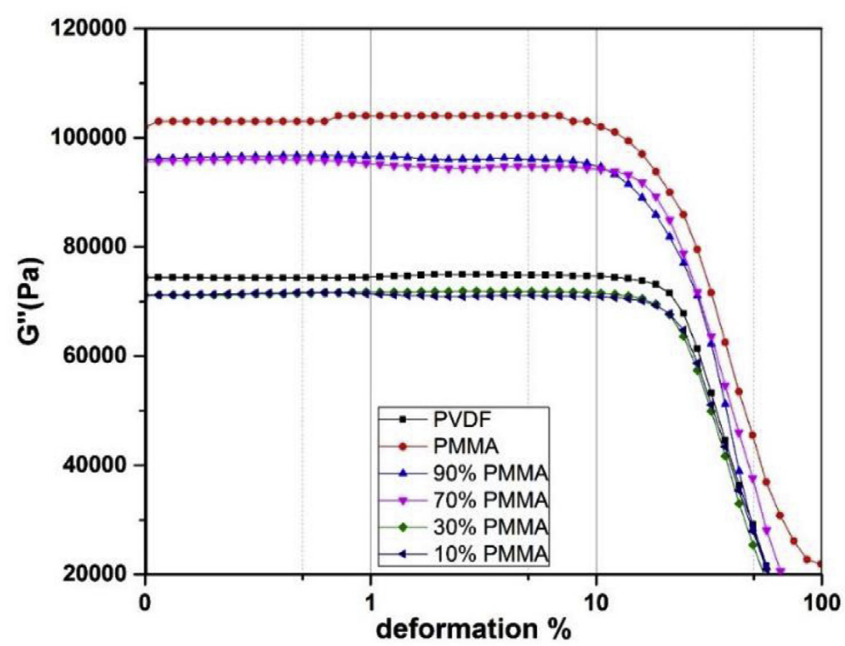

Fig. 7. Identification of the LVE region by rheological test (imaginary shear modulus versus shear deformation) for PVDF/PMMA blends.

\subsection{Numerical simulation}

The solver used in this study to reproduce the coalescence phenomenon between PVDF and PMMA droplets has the following characteristics [33]: mixture diphase solver, unsteady, incompressible and laminar flow model, first order implicit time solver, second order space scheme. Concerning the computational domain, a grid made of structured quadrilateral cells (performed by Gambit), is used.

\subsubsection{Viscosity ratio effect}

A first series of several simulations has been launched to study the effect of the viscosity ratio $\eta_{1} / \eta_{2}$ on the coalescence between a grain of PVDF and PMMA. Table 4 summarizes different values of the viscosity ratios used during the tests carried out (the real ratio between the study case is 3 ). The grains are supposed to have the same initial size (radius $\left.\mathrm{a}_{0}\right)$.

Fig. 9 presents the simulation result in the case of the highest viscosity ratio (Test 1 ). As expected, although both polymers exhibit a

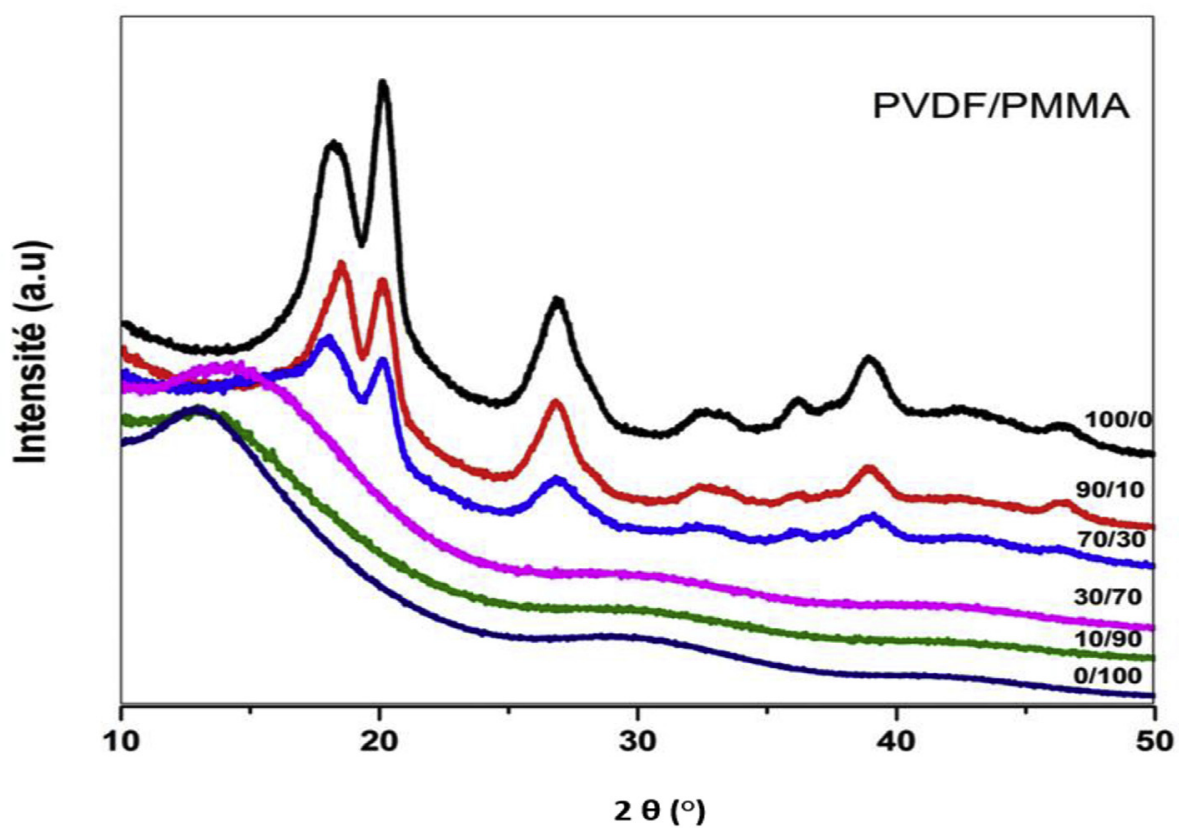

Fig. 6. WAXS patterns of PVDF/PMMA blends. 


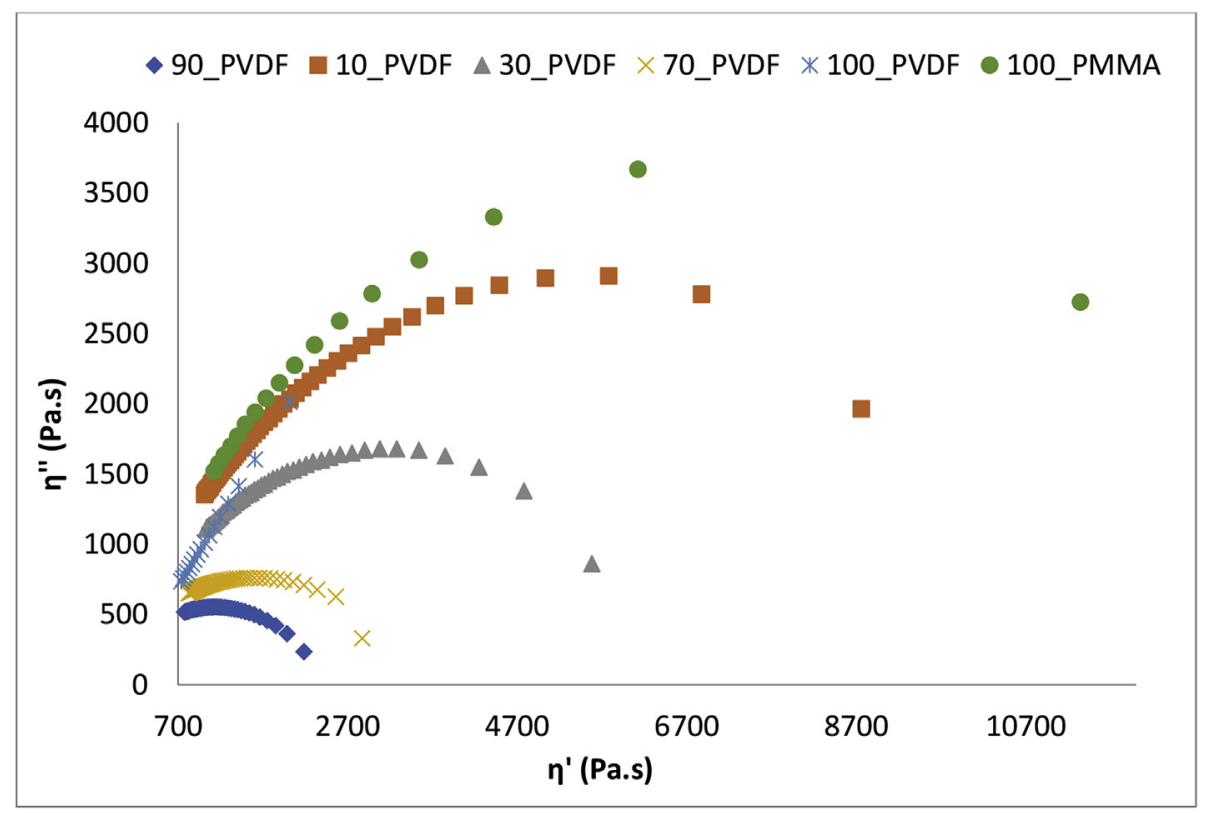

Fig. 8. Cole -Cole plots of the PVDF/PMMA blends $\left(\mathrm{T}=220^{\circ} \mathrm{C}, \mathrm{f}=1 \mathrm{~Hz}\right)$.

Table 3

Evolution of the interaction parameter as a function of the PMMA content in the PVDF/PMMA mixtures.

\begin{tabular}{llll}
\hline$\nu_{1}$ & 0.08 & 0.25 & 0.59 \\
\hline$\nu_{1}^{2}$ & 0.007 & 0.06 & 0.34 \\
$\boldsymbol{T}_{\boldsymbol{m}}(\mathrm{K})$ & 445 & 442 & 436 \\
$\chi_{12}$ & -0.56 & -0.54 & -0.26 \\
\hline
\end{tabular}

Table 4

Different study cases for the numerical simulation.

\begin{tabular}{ll}
\hline Tests & $\frac{\eta_{2}}{\eta_{1}}$ \\
\hline Test 01 & 10 \\
Test 02 & 3 \\
Test 03 & 1.2 \\
\hline
\end{tabular}

certain degree of interaction and miscibility, a high difference of viscosities between the two materials does not promote their coalescence. The grain whose viscosity is higher keeps its initial state (solid) and the second grain collapses very quickly.

By contrast, considering the results shown in Fig. 10, (a), when the viscosity ratio is lower (present case of PVDF and PMMA polymers), the two polymers droplets melt and collapse to form an important interface. The reduction of the viscosity ratio $\eta_{1} / \eta_{2}$ between the two materials is a favorable parameter which dictates the simulation of the coalescence phenomenon. One can also measure the thickness of the formed interphase in this case using the Fluent post-processing software. The result is shown in Fig. 10, (b).

In this case of a lower viscosity ratio taken equal to 1.2 , (Test 3 ), the result shows that the two grains merge and the formed interface is larger with the presence of a small air bubble that remains trapped between the grains. This phenomenon is very realistic since it reproduces what could happen during the sintering phenomenon of polymer grains for which the formation and imprisonment of air bubbles can be observed (Fig. 11 a). However, the formation of a sharp peak at the top of grains arises during the simulation, while this is not reproducible in lab tests. Indeed, the formation of the peak is more

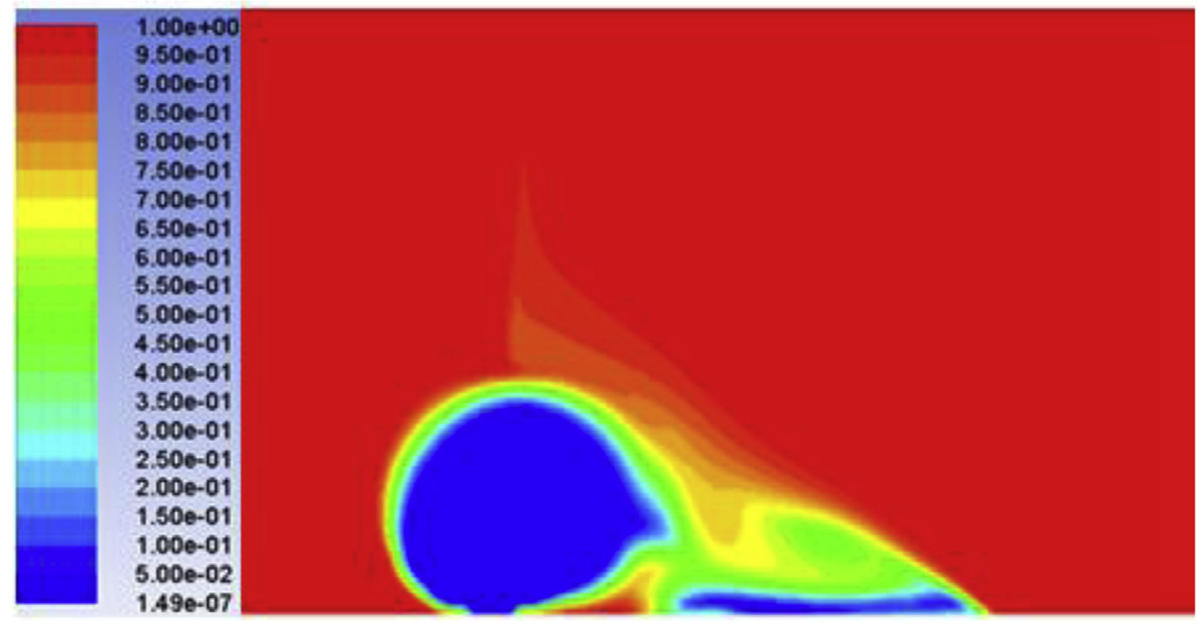

Fig. 9. Numerical simulation of the coalescence phenomenon as function of the density, (Test 1: Viscosity ratio equal to 10). 

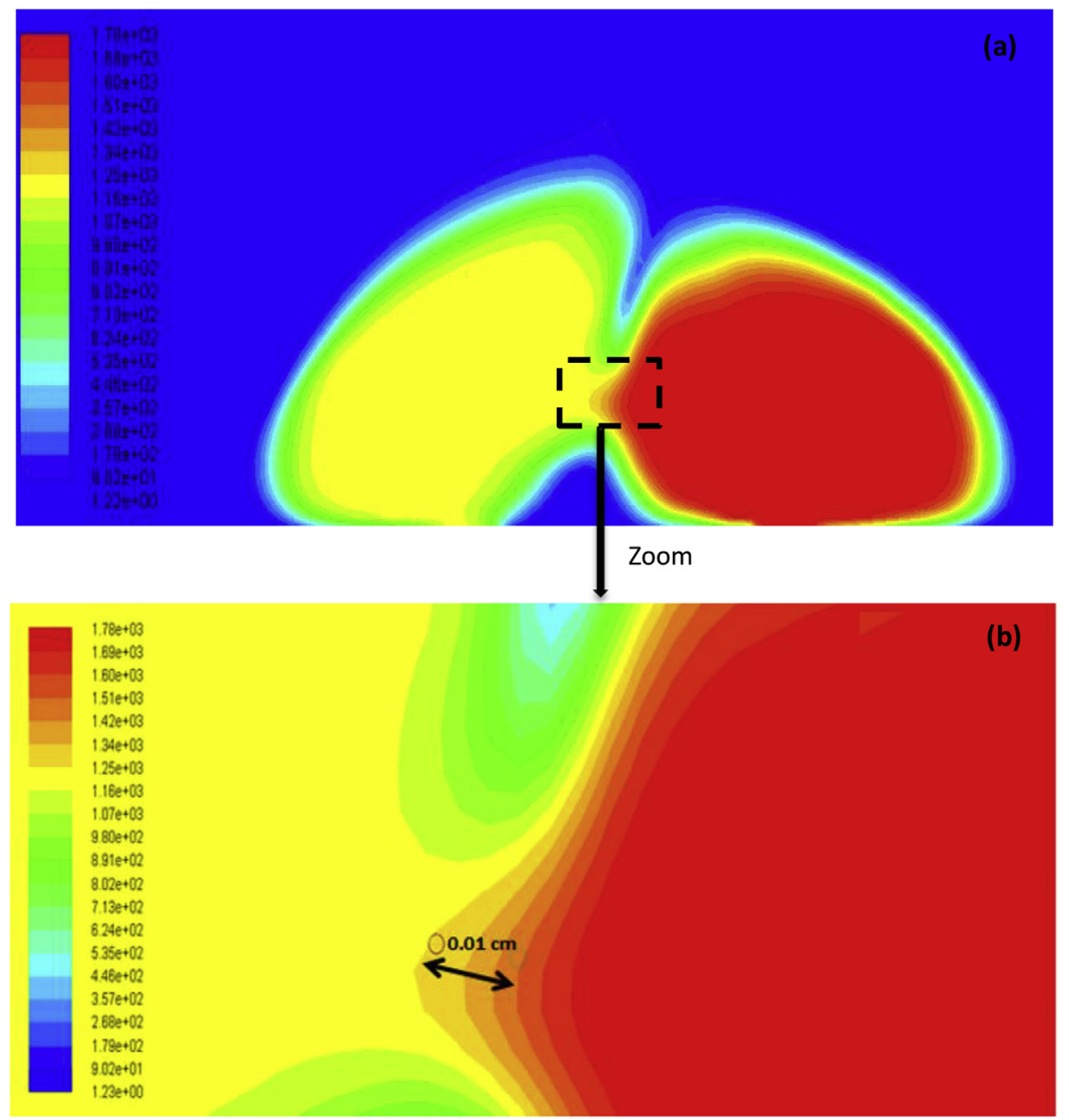

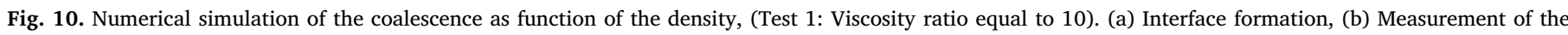
interphase thickness.

likely to be due to the numerical model used here, "Mixture", which assumes that all the phases involved in the system are miscible and therefore considers that the air is also a miscible phase with the two polymers. To better highlight the interdiffusion between the two grains in contact, Fig. $11 \mathrm{~b}$ shows a zoom of the interface, as function of the density. As expected, one can see that the interface is a mixture zone of the two phases involved with different proportions illustrated by the color gradient. The measurement of this interface shows a variation in the thickness of the latter $(0.043 \mathrm{~cm})$ compared to the previous case $(0.01 \mathrm{~cm})$. This increase can be explained by the fact that the decrease in the viscosity ratio between both polymers promotes their interdiffusion and thus the formation of a larger interface.

\subsubsection{Size grain influence}

In a previous work of the authors [25], it was highlighted through the experimental investigation of the coalescence test performed on PVDF/PMMA pair, that the initial size of the grain is an influent parameter which impacts the coalescence kinetic [34]. In fact, in the case of grains of the same polymer, smaller grain size induces faster kinetics of coalescence [35,36]. In this paper, which deals with grains of two different polymers, it has been observed that the smaller size of the more viscous polymer (here, PMMA) promotes the coalescence mechanism. Thus, by analogy to the experimental tests, the effect of the particle size is investigated by numerical simulation during the coalescence of miscible polymers. From now, two cases were considered for study; the first one corresponds to a reduced initial radius of polymer 1 and the second case deals with the reduction of the size of polymer 2 .
The ratio viscosity considered for both cases was taken equal to 3 , which corresponds to the real ratio used in lab assays. Simulation results are presented in Figs. 12 and 13.

The reduction of the grain size allows in both cases a better collapse of the two grains as well as a faster coalescence phenomenon, as observed from numerical simulation results. It was also found that in the case 2 (smaller size of the more viscous polymer P2), the coalescence process is faster, which correlates very well with the experimental findings [25].

\section{Conclusion}

The PMMA polymer induces a decrease of the chemical potential of the PVDF in the blends, which results in a reduction of the melting point at the equilibrium.

The interaction parameter was found to be negative for the different mixtures of PVDF/PMMA, which is a thermodynamic indication of the stability of the blend and thereby the miscibility of its components.

Numerical simulations have been undertaken to investigate the viscosity and grain size ratios effect on the coalescence process. It has been demonstrated that PVDF and PMMA merge progressively to form a single particle due to the interdiffusion of the two initial droplets.

The proposed numerical approach has demonstrated good agreement with lab work in describing the formation and the evolution of the interface between the two particles during the coalescence process. Developed numerical method has been shown useful to save time and long experimental laboratory work to investigate the miscibility of two 

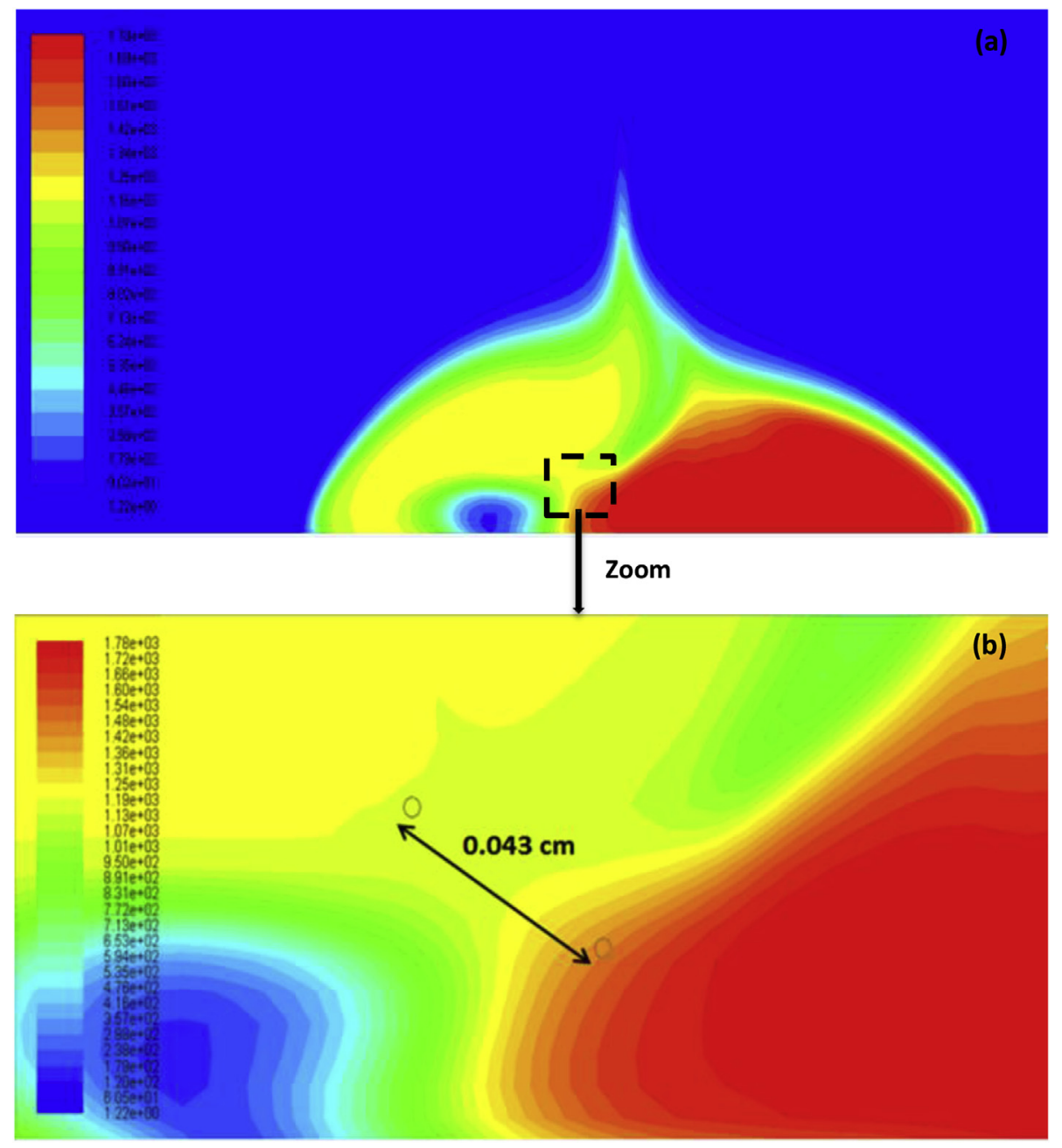

Fig. 11. Numerical simulation of the coalescence as function of the density: (a) with a viscosity ratio equal to 1.2. (b) Thickness interface measurement.

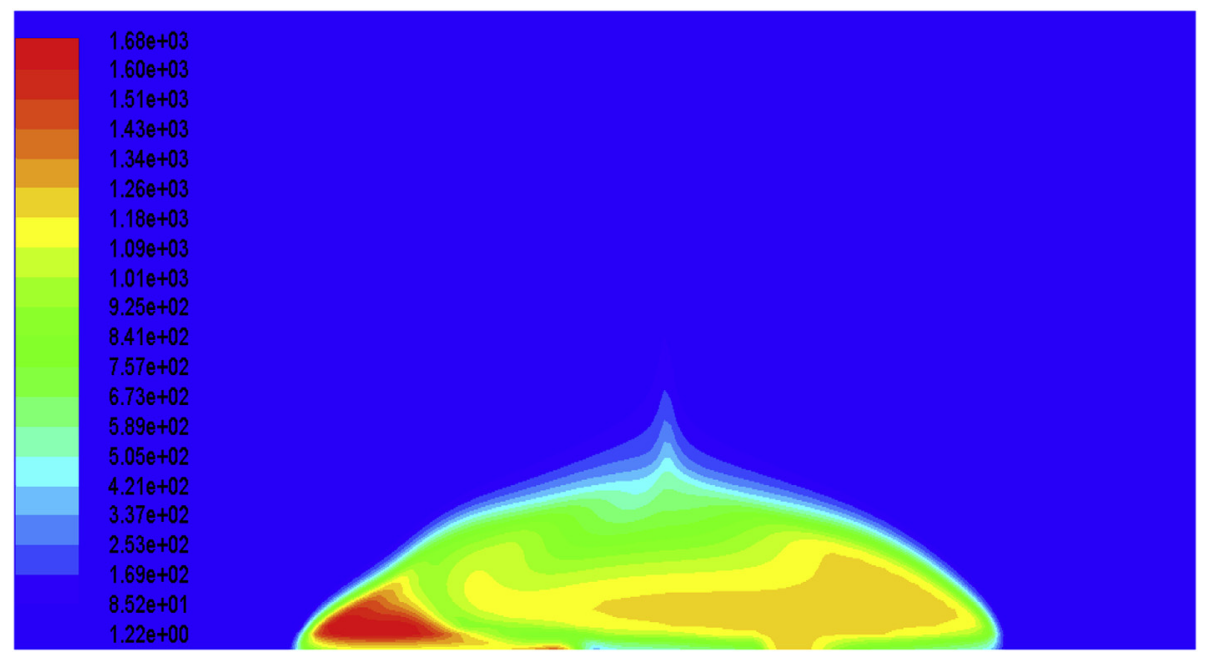

Fig. 12. Numerical simulation results (Case 1: PMMA radius is reduced).

different polymers.

Further work is currently taking place to produce a generalized numerical method to enable the simulation of the sintering phenomenon during densification of grains of different polymers. This scenario is representative of the industrial molding process for which powder containing particles of different polymers are put together to obtain a new molded product, such as in rotational molding. The achievement of such challenge could help minimizing the molding time and optimize the polymer processing. 


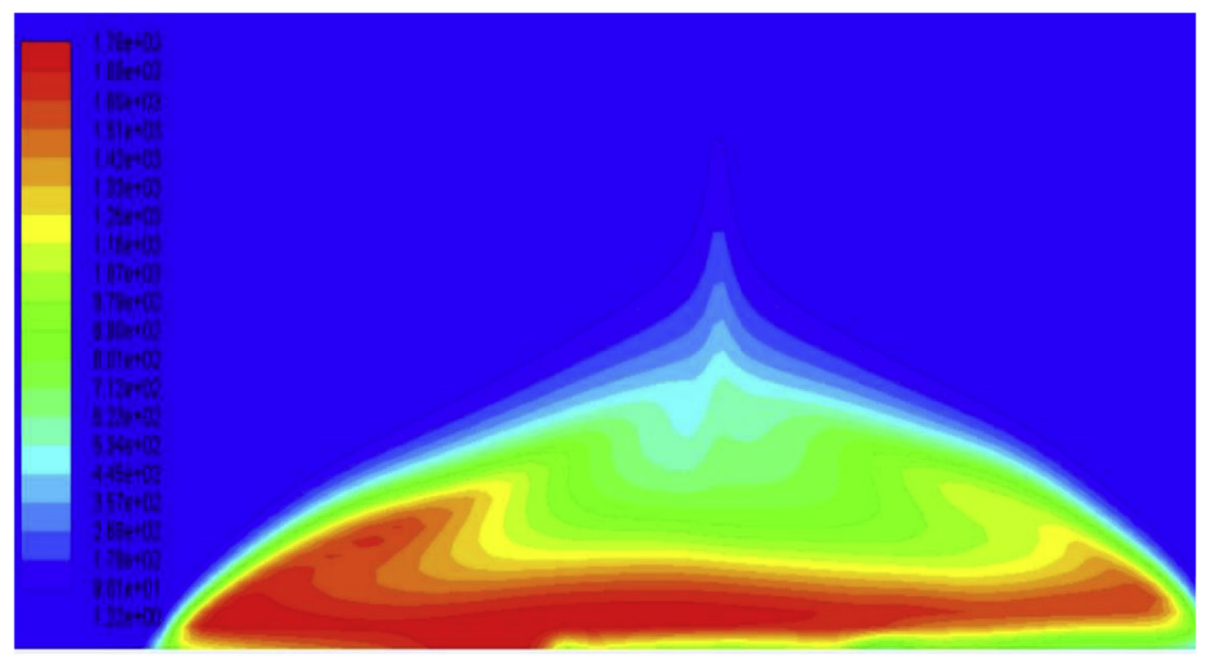

Fig. 13. Numerical simulation results (Case 2: PVDF radius is reduced).

\section{Acknowledgement}

The authors would like to gratefully acknowledge the financial support of the Chaire Mines Urbaines, Eco-Systemes and ParisTech Fondation.

\section{References}

[1] S. Aid, A. Eddhahak, Z. Ortega, et al., Experimental study of the miscibility of ABS/ PC polymer blends and investigation of the processing effect, J. Appl. Polym. Sci. 134 (25) (2017) 44975.

[2] X. Zhao, S. Chen, J. Zhang, et al., Crystallization of PVDF in the PVDF/PMMA blends precipitated from their non-solvents: special "orientation" behavior, morphology, and thermal properties, J. Cryst. Growth 328 (2011) 74-80.

[3] W. Li, H. Li, Y.-M. Zhang, Preparation and investigation of PVDF/PMMA/TiO2 composite film, J. Mater. Sci. 44 (2009) 2977-2984.

[4] F.-C. Chiu, C.C. Chen, Y.-J. Chen, Binary and ternary nanocomposites based on PVDF, PMMA, and PVDF/PMMA blends : polymorphism, thermal, and rheological properties, J. Polym. Res. 21 (2014) 378.

[5] S. Mohamadi, N. Sharifi-Sanjani, Investigation of the crystalline structure of PVDF in PVDF/PMMA/graphene polymer blend nanocomposites, Polym. Compos. 32 (2011) 1451-1460.

[6] I.S. Elashmawi, N.A. Hakeem, Effect of PMMA addition on characterization and morphology of PVDF, Polym. Eng. Sci. 48 (2008) 895-901.

[7] P. Martins, A.C. Lopes, S. Lanceros-Mendez, Electroactive phases of poly(vinylidene fluoride): determination, processing and applications, Prog. Polym. Sci. 39 (2014) 683-706.

[8] A. Salimi, A.A. Yousefi, Analysis method: FTIR studies of $\beta$-phase crystal formation in stretched PVDF films, Polym. Test. 22 (2003) 699-704.

[9] S. Schneider, X. Drujon, J.C. Wittmann, B. Lotz, Impact of nucleating agents of PVDF on the crystallization of PVDF/PMMA blends, Polymer 42 (2001) 8799-8806.

[10] W. Ma, J. Zhang, X. Wang, S. Wang, Effect of PMMA on crystallization behavior and hydrophilicity of poly(vinylidene fluoride)/poly(methyl methacrylate) blend prepared in semi-dilute solutions, Appl. Surf. Sci. 253 (2007) 8377-8388.

[11] D.W. Seong, J.S. Yeo, S.H. Hwang, Fabrication of polycarbonate blends with poly (methyl methacrylate-co-phenyl methacrylate) copolymer: miscibility and scratch resistance properties, J. Ind. Eng. Chem. 36 (2016) 251-254.

[12] H. Yoshida, Structure formation of PVDF/PMMA blends studied, J. Therm. Anal. 49:101-105.

[13] M.M. Coleman, J. Zarian, D.F. Varnell, P.C. Painter, A fourier transform infrared study of polymer blends. I. Poly(vinylidene fluoride) — poly(methyl methacrylate) system, J. Polym. Sci. C Polym. Lett. 15 (1977) 745-750.

[14] C. Huang, L. Zhang, Miscibility of poly(vinylidene fluoride) and atactic poly(methyl methacrylate), J. Appl. Polym. Sci. 92 (2004) 1-5.

[15] Y. Kita, K. Kishino, K. Nakagawa, Synthesis of N-cyclohexylmaleimide for heat-resistant transparent methacrylic resin, J. Appl. Polym. Sci. 63 (1997) 363-368.

[16] C.T. Bellehumeur, M.K. Bisaria, J. Vlachopoulos, An experimental study and model assessment of polymer sintering, Polym. Eng. Sci. 36 (1996) 2198-2207.

[17] C.T. Bellehumeur, M. Kontopoulou, J. Vlachopoulos, The role of viscoelasticity in polymer sintering, Rheol. Acta 37 (1998) 270-278.

[18] T. Nishi, T.T. Wang, Melting point depression and kinetic effects of cooling on crystallization in poly (vinylidene fluoride)-Poly(methyl methacrylate) mixtures, Macromolecules 8 (1975) 909-915.

[19] D.F. Fletcher, Mécanique des fluides numérique, Techniques Ingénieur, 2004.

[20] P. Helluy, O. Hurisse, E. Le Coupanec, Verification of a two-phase flow code based on an homogeneous model, Int. J. Finite 13 (2016).

[21] G. Chanteperdrix, Modélisation et simulation numérique d'écoulement diphasique à interface libre: Application à l'étude des mouvements de liquide dans les réservoirs des véhicules spatiaux, (2004).

[22] D. Gerlach, G. Tomar, G. Biswas, F. Durst, Comparison of volume-of-fluid methods for surface tension-dominant two-phase flows, Int. J. Heat Mass Tran. 49 (2006).

[23] J. Kreeft, B. Koren, A new formulation of Kapila's five equation model for compressible two-fluid flow and its numerical treatment, J. Comput. Phys. 229 (2010).

[24] J.M. Lopez Herrera, S. Popinet, M.A. Herrada, A charge conservative approach for simulating electrohydrodynamic two-phases flows using volume of fluid, J. Comput. Phys. 230 (2011).

[25] G. Tomar, D. Gerlach, G. Biswas, N. Alleborn, A. Sharma, F. Durst, S.W.J. Welch, A. Delgado, Two-phase electrohydrodynamic simulations using a volume-of-fluid approach, J. Comput. Phys. 227 (2007).

[26] Y.D. Wang, M. Cakmak, Hierarchical structure gradients developed in injection-molded PVDF and PVDF-PMMA blends. I. Optical and thermal analysis, J. Appl. Polym. Sci. 68 (1998) 909-926.

[27] S. Ray, A.J. Easteal, R.P. Cooney, N.R. Edmonds, Structure and properties of meltprocessed PVDF/PMMA/polyaniline blends, Mater. Chem. Phys. 113 (2009) 829-838.

[28] S. Thomas, Y. Grohens, P. Jyotishkumar, Characterization of Polymer Blends: Miscibility, Morphology and Interfaces, John Wiley \& Sons, 2014.

[29] W. Brostow, H.E. Hagg Lobland, Materials: Introduction and Applications, John Wiley \& Sons, 2017.

[30] U.W. Gedde, Polymer Physics, Kluwer Academic Publ., Dordrecht, Netherlands; Norwell, MA, 2001

[31] C. Chevallier, F. Becquart, M. Taha, Polystyrene/polycarbonate blends compatibilization: morphology, rheological and mechanical properties, Mater, Chem. Phys. 139 (2013) 616-622.

[32] H. Yoshida, Structure formation of PVDF/PMMA blends studied: simultaneous DSC/ FT-IR measurement, J. Therm. Anal. 49 (1997) 101-105.

[33] FLUENT 6.3 User's Guide. https://www.sharcnet.ca/Software/Fluent6/html/ug/ main_pre.htm. Accessed 20 Sep 2018.

[34] S. Aid, A. Eddhahak, Z. Ortega Z, et al., Predictive coalescence modeling of particles from different polymers: application to PVDF and PMMA pair, J. Mater. Sci. 52 (2017).

[35] M. Asgarpour, Analyse et modélisation de la coalescence et de la densification des grains de polymére lors du procédé de rotomoulage, (2010).

[36] A. Hamidi, S. Farzaneh, F. Nony, et al., Modelling of sintering during rotational moulding of the thermoplastic polymers, Int. J. Material Form. 9 (2016) 519-530. 